\title{
Boron Carbide Nanowires from Castor Oil for Optronic Applications: A Low-Temperature Greener Approach
}

\section{H. V. Saritha Devi}

University of Kerala

M. S. Swapna

University of Kerala

S SANKARARAMAN ( $\nabla$ drssraman@gmail.com )

University of Kerala

\section{Research Article}

Keywords: boron carbide, nanowires, condensation method, castor oil

Posted Date: August 18th, 2020

DOI: https://doi.org/10.21203/rs.3.rs-60234/v1

License: (c) (i) This work is licensed under a Creative Commons Attribution 4.0 International License.

Read Full License 


\section{Abstract}

The development of one-dimensional nanostructures has revolutionized electronic and photonic industries because of their unique properties. The present paper reports the low-temperature green synthesis of boron carbide nanowires, of diameter $14 \mathrm{~nm}$ and length $750 \mathrm{~nm}$, by the condensation method using castor oil as the carbon precursor. The nanowires synthesized exhibit beaded chain morphology, and bandgap energy of $2.08 \mathrm{eV}$ revealed through the Tauc plot analysis. The structure of boron carbide nanowires is revealed by Fourier transform infrared spectroscopy and X-ray diffraction analyses. The photoluminescence study reveals the nanowire's blue light emission capability under ultraviolet excitation, which is substantiated by the CIE plot suggesting its potential in photonic applications.

\section{Introduction}

Nanoscale materials have received considerable attention employing their unique properties and a wide range of applications relative to their bulk counterparts [1, 2]. Nanomaterials can be classified into zero-, one-, and two- dimensional structures depending on the shape and size. Among the one dimensional (1D) nanostructures, nanowires play a significant role in device fabrication [3-5]. The properties of the nanomaterials are strongly influenced by their size, shape, and morphology. The diameter $(<10 \mathrm{~nm})$ of the nanowires (NWs) introduces quantum-confined size effects, modifying the structural, electronic, optical, thermal, and magnetic properties. This enables its use in micro and nanoelectromechanical systems, sensors, and photodetectors [1, 6-9]. The wide bandgap exhibited by NWs makes it suitable for applications in light-emitting diodes, photovoltaics, and nanoscale lasers [1, 10]. NWs having hightemperature stability and high-frequency performance are essential in the development of electronic and optoelectronic systems.

Of different materials - metals, polymers, semiconductors, insulators, and ceramics - NWs of ceramic materials have gained attention recently due to their characteristic properties and widespread applications in the area of magnetic nanocomposites, quantum electronic materials, gas separations, and structural reinforcements. Ceramic materials are high strength materials and are chemically and thermally stable. Among ceramic materials, boron carbide (BC) finds widespread applications lightweight armors, blast nozzles, ceramic bearing, brake linings, cutting tools, rocket propellant in the aerospace industry, and neutron absorber and shielding material in the nuclear industry [11-14] - due to its unique properties - greater hardness, high thermal and chemical stability, high neutron absorption cross-section, corrosion resistivity, and high melting point [15-17]. The lower fracture toughness of bulk $\mathrm{BC}$ is overcome by the 1D BC nanostructures having high elastic modulus [18]. The enhanced physical and electrical properties of $\mathrm{BC}$ NWs are responsible for the high temperature and power applications. The field emission properties of BC NWs make them a potential candidate as cathode materials $[19,20]$.

The performance of 1D BC nanostructures is greatly influenced by the synthesis condition [21]. Several methods, such as template-based synthesis, microwave radiation, chemical vapor deposition, and 
synthesis using polymer precursors, are available to produce different morphological structures of BC [22-28]. Zhang et al. [29] synthesized BC nanowires using a plasma-enhanced chemical vapor deposition method, and high pure BC NWs are prepared by Ma et al. using the thermal evaporation method [30]. Most of these methods need pre-process conditions such as catalyst preparation, substrate, and template preparation. Despite these methods, a more convenient low-temperature method for producing BC NWs has high demand and interest.

The condensation method is one of the low-temperature synthesis methods used for BC's production using inexpensive organic precursors such as glycerin, citric acid, and polyvinyl alcohol (PVA) [31-33]. The usage of polymeric precursors enables control over the final product's properties and structures by varying the precursor composition at low-temperatures $[11,34,35]$. Based on the above advantages of polymeric precursors, the bulk BC structure can be tailored to NWs by choosing the correct precursor ratio and suitable synthesis temperature. In this research work, a low-temperature condensation method is selected to synthesize BC NWs using readily available natural carbon source, castor oil.

\section{Experimental}

Of different synthesis methods for the formation of NWs, the solution-based approach is more suitable. The structure can be controlled by varying the precursor ratio and synthesis temperature. The use of organic precursors, for the formation of $\mathrm{BC}$, facilitates the dispersibility and uniformity of boron and carbon sources. Among boron sources, boric acid enhances the esterification process due to the liberation of hydroxyl groups [31,36]. For the synthesis of BC, boric acid (Sigma-Aldrich) and castor oil (Indian pharmaceuticals) are used as the boron and carbon sources in the ratio of 1:4, respectively, by condensation reaction method. Initially, boric acid is added to the heated castor oil. The mixture is refluxed with the help of a heating mantle at a temperature of $75-80^{\circ} \mathrm{C}$ until all the moisture content is vaporized from the mixture. The mixture's golden yellow gel is transferred to white solid after the reaction and is subjected to pre-treatment at $300^{\circ} \mathrm{C}$ for three hours to get the dry powder. The crushed powder is then heat-treated at $900^{\circ} \mathrm{C}$ for two hours in a tubular furnace with a continuous nitrogen gas flow. The obtained powder is annealed at $600^{\circ} \mathrm{C}$ in the air $(1 \mathrm{~h})$ to remove unreacted carbon to get the $\mathrm{BC}$ sample.

The BC sample synthesized is subjected to different morphological, structural, and compositional analyses using field emission scanning electron microscope (FESEM - Nova Nano), X-ray diffractometer (XRD - Bruker d8 Advance), and Fourier transform infrared spectrometer (FTIR - Thermo Fisher iS50) in attenuated total reflectance mode in the region $4000-400 \mathrm{~cm}^{-1}$. The product's optical properties are also studied by UV-visible absorption (UV-Vis- Jasco V550) and photoluminescence (PL- Horiba Fluoromax) spectroscopic methods.

\section{Results And Discussion}

The formation of 1D BC NWs can be understood from the FESEM images shown in Fig. 1. The morphological modifications of the sample before and after the heat treatment at $900{ }^{\circ} \mathrm{C}$ are analyzed. 
From Fig. 1, the transformation of morphology to 1D NWs, upon annealing to $900{ }^{\circ} \mathrm{C}$, is evident. The images given at different magnification ( $\mathrm{nm}$ to $\mu \mathrm{m}$ scale) indicate the formation of NWs over a large area. Figure 1 also reveals the formation of 1D NWs, of diameter $14 \mathrm{~nm}$ and length up to $750 \mathrm{~nm}$, at $900{ }^{\circ} \mathrm{C}$ from the nanolayers appearing at $300^{\circ} \mathrm{C}$. A closer examination of the NWs (from Fig. $1(\mathrm{~d})$ ) reveals a beaded chain morphology responsible for the surface roughness.

(c) and (d) annealed at $900^{\circ} \mathrm{C}$.

The structure of the compounds formed is identified through the XRD analysis. The XRD pattern of the sample with NW morphology (Fig. 2) shows a high-intensity peak at $27.5^{\circ}$ due to the orthorhombic BC (ICDD file No. 00-026-0232) and the peaks at $30^{\circ}, 34^{\circ}, 39^{\circ}, 42^{\circ}, 54^{\circ}, 60^{\circ}, 66^{\circ}$ indicated the presence of rhombohedral BC (ICDD file No. 00-019-0178 and 00-035-0798). When compared to standard patterns, the broadening and shifting of peaks at $34^{\circ}$ and $39^{\circ}$ can be attributed to the crystal defect, twins [37-40]. The FTIR spectrum, Fig. 3, showing the molecular species' vibrational modes can be used for understanding the structure of the sample. The characteristic peak at $1398 \mathrm{~cm}^{-1}$ present in the BC NWs is assigned to boron icosahedra, indicating more boron in the sample. When the peaks around 627 and $1190 \mathrm{~cm}^{-1}$ correspond to the $B-C$ stretching vibration, those in the region $550-410 \mathrm{~cm}^{-1}$ (shown as an inset of Fig. 4) show the C-B-C bending vibrations [35, 41]. B-C and C-B-C bands' presence indicates the complete reaction between boric acid and castor oil with the formation of borate ester bonds and hence confirms the formation of boron rich BC. The other bands around $3200 \mathrm{~cm}^{-1}$ and

$2260 \mathrm{~cm}^{-1}$ are assigned to $-\mathrm{OH}$ and $\mathrm{C}-\mathrm{O}$ stretching vibrations.

The determination of the bandgap energy of $\mathrm{BC}$ is essential for its application in electronics and optoelectronics. The variation in the stoichiometry of $B C$ varies the bandgap from $0.4 \mathrm{eV}$ to $2.7 \mathrm{eV}$ [ $41-$ 43]. Figure 4(a) shows the UV-Vis absorption spectrum of the BC NW and shows a maximum absorption around $265 \mathrm{~nm}$ due to the $\mathrm{C}=0 \mathrm{n}-\pi^{\star}$ transition in the $s p^{3}$ hybrid region. The direct bandgap energy of the BC NWs calculated from the Tauc plot (Fig. 4(b)) is obtained as $2.08 \mathrm{eV}$. The PL spectrum of BC NWs, Fig. 5(a), for the excitations at $270 \mathrm{~nm}$ and $300 \mathrm{~nm}$ shows a broad emission with the peak centered around $410 \mathrm{~nm}$. The human eye's color perception can be understood from the CIE plot [44] shown in Fig. $5(\mathrm{~b})$. The CIE coordinates for the two excitations $(0.148,0.039)$ and $(0.144,0.047)$ fall in the chromaticity diagram's blue region. The distribution of emitted energy at different wavelengths can be understood from the power spectrum shown in Fig. 5(c) and (d).

(c) the power spectrum for $\lambda_{\mathrm{ex}^{-}} 270 \mathrm{~nm}$ and (d) power spectrum for $\lambda_{\mathrm{ex}}{ }^{-} 300 \mathrm{~nm}$.

\section{Conclusion}

The present paper reports the low-temperature green synthesis of BC NWs by condensation method using castor oil as the carbon precursor. The 1D BC nanostructures have emerged as an important class of technologically significant material. Of various synthesis methods, employing sophisticated equipment 
and toxic chemicals, eco-friendly approaches are highly relevant and became the focus of research. As an organic precursor, castor oil facilitates the dispersibility with boric acid, boron source, and forms the NWs through the condensation reaction. The FESEM analysis of the BC NWs exhibit beaded chain morphology of diameter $14 \mathrm{~nm}$ and length $750 \mathrm{~nm}$. The UV-Vis spectroscopic analysis indicates a direct bandgap of energy $2.08 \mathrm{eV}$. The XRD analysis shows a high-intensity peak at $27.5^{\circ}$ due to the orthorhombic $\mathrm{BC}$, and the peaks at $30^{\circ}, 34^{\circ}, 39^{\circ}, 42^{\circ}, 54^{\circ}, 60^{\circ}, 66^{\circ}$ suggests the presence of rhombohedral BC. The FTIR spectrum shows the $B-C$ stretching vibration and $C-B-C$ bending vibrations confirming the nanowire to be boron carbide. The PL spectrum recorded for the excitations 270 and $300 \mathrm{~nm}$ shows a peak at $410 \mathrm{~nm}$. The CIE plot shows the coordinates corresponding to the emission $(0.148,0.039)$ and $(0.144,0.047)$ in the blue region. The attractive thermal, physical, and electrical properties of $\mathrm{BC}$ NWs make it suitable in power applications and as cathode materials. Thus, the study reveals the possibility of green synthesis of 1D BC NWs using castor oil as the natural carbon source for potential photonic and electronic applications.

\section{Declarations}

\section{Acknowledgment}

The author H.V. Saritha Devi is grateful to Kerala State Council for Science, Technology and Environment (KSCSTE) for the financial support.

\section{References}

1. Meyyappan M, Sunkara MK (2009) Inorganic Nanowires: Applications, Properties, and Characterization. CRC Press, Boca Raton

2. Guisbiers G, Mejía-Rosales S, Leonard Deepak F (2012) Nanomaterial Properties: Size and Shape Dependencies. J Nanomater. http:// doi.org/ 10.1155/2012/180976

3. Dasgupta NP, Sun J, Liu C et al (2014) 25th Anniversary Article: Semiconductor NanowiresSynthesis, Characterization, and Applications. Adv mater 26:2137-2184

4. Mcllroy DN, Alkhateeb A, Zhang D et al (2004) Nanospring formation-unexpected catalyst mediated growth. J Phys Condens Matter 16:415-440

5. Zhang Y, Ram MK, Stefanakos EK et al (2012) Synthesis, Characterization, and Applications of ZnO Nanowires. J Nanomater. http://dx.doi.org/10.1155/2012/624520

6. Zhang X, Wang G, Liu X et al (2008) Different CuO nanostructures: synthesis, characterization, and applications for glucose sensors. J Phys Chem C 112:16845-16849

7. Xia Y, Yang P, Sun Y et al (2003) One-Dimensional Nanostructures: Synthesis, Characterization, and Applications. Adv Mater 15:353-389

8. Devan RS, Patil RA, Lin JH et al (2012) One-dimensional metal-oxide nanostructures: Recent developments in Synthesis, Characterization, and Applications. Adv Funct Mater 22:3326-3370 
9. Khalil A, Singh Lalia B, Hashaikeh R et al (2013) Electrospun metallic nanowires: Synthesis, characterization, and applications. J Appl Phys 114:171301

10. Cheng C, Fan HJ (2012) Branched nanowires: synthesis and energy applications. Nano Today 7:327-343

11. Mondal S, Banthia AK (2005) Low-temperature synthetic route for boron carbide. J Eur Ceram Soc 25:287-291

12. Suri AK, Subramanian C, Sonber JK et al (2010) Synthesis and consolidation of boron carbide: a review. Int Mater Rev 55:4-40

13. Sarıyer $D$, Küçer R, Küçer N (2015) Neutron shielding properties of concretes containing boron carbide and ferro-boron. Procedia-Social Behavioral Sciences 195:1752-1756

14. Liu LL, He GG, Wang YH et al (2017) Ignition and Combustion Performance of the Primary Condensed-phase Combustion Products from Boron-based Fuel-rich Propellants. Cent Eur J Energ Mater 14:1-13

15. Saritha Devi HV, Swapna MS, Raj V et al (2018) Natural cotton as precursor for the refractory boron carbide-a hydrothermal synthesis and characterization. Mater Res Express 5:015603

16. Saritha Devi HV, Swapna MS, Ambadas G et al (2018) Hydrothermal development and characterization of the wear-resistant boron carbide from Pandanus. a natural carbon precursor. Appl Phys A 124:297

17. Saritha Devi HV, Swapna MS, Ambadas G et al (2018) Low-temperature green synthesis of boron carbide using aloe vera. Chin Phys B 27:107702

18. Tao X, Dong L, Wang X et al (2010) B4C-Nanowires/Carbon-Microfiber Hybrid Structures and Composites from Cotton T-shirts. Adv Mater 22:2055-2059

19. Ji-Fa T, Li-Hong B, Xing-Jun W et al (2008) Probing field emission from boron carbide nanowires. Chin Phys Lett 25:3463

20. Huang Y, Liu F, Luo Q et al (2012) Fabrication of patterned boron carbide nanowires and their electrical, field emission, and flexibility properties. Nano Res 5:896-902

21. Zhang $\mathrm{Y}$, Zhang $\mathrm{Y}$, Gong $\mathrm{H}$ et al (2016) Microwave-assisted sol-gel synthesis of neutron-absorbed nano-sized ${ }^{10} \mathrm{~B}$-enriched $\mathrm{B}_{4} \mathrm{C}$ powders. J Sol-Gel Sci Technol 80:683-689

22. Sneddon LG, Pender MJ, Forsthoefel KM et al (2005) Design, syntheses and applications of chemical precursors to advanced ceramic materials in nanostructured forms. J Eur Ceram Soc 25:91-97

23. Li-Hong B, Chen L, Yuan T et al (2008) Synthesis and photoluminescence property of boron carbide nanowires. Chinese Phys B 17:4585-4507

24. Rodríguez MG, Kharissova OV, Ortiz-Mendez U (2004) Formation of boron carbide nanofibers and nanobelts from heated by microwave. Rev Adv Mater Sci 7:55-60

25. Chang B, Gersten BL, Szewczyk ST et al (2006) Towards the preparation of boron carbide nanorods by carbothermal reaction method. In NSTI-Nanotech 1:369-372 
26. Velamakanni A, Ganesh KJ, Zhu Y et al (2009) Catalyst-Free Synthesis and Characterization of Metastable Boron Carbide Nanowires. Adv Funct Mater 19:3926-3933

27. Ma R, Bando Y (2002) Investigation on the growth of boron carbide nanowires. Chem Mater 14:4403-4407

28. Pender MJ, Forsthoefel KM, Sneddon LG (2003) Molecular and polymeric precursors to boron carbide nanofibers, nanocylinders, and nanoporous ceramics. Pure Appl Chem 75:1287-1294

29. Zhang D, Mcllroy DN, Geng Y et al (1999) Growth and characterization of boron carbide nanowires. J Mater Sci Lett 18:349-351

30. Ma R, Bando Y (2002) High purity single crystalline boron carbide nanowires. Chem Phys Lett 364:314-317

31. Rafi-ud-din, Zahid GH, Asghar Z et al (2014) Ethylene glycol assisted low-temperature synthesis of boron carbide powder from borate citrate precursors. J Asian Ceram Soc 2:268-274

32. Amir F, Naser E, Mehdi R et al (2012) Synthesis of boron carbide nano particles using polyvinyl alcohol and boric acid. Ceram -Silik 56:32-35

33. Shawgi N, Wang S, Wang Z et al (2017) Synthesis of nano particles and fiber-like shape boron carbide powder from ploy (vinyl alcohol) and boric acid. J Sol-Gel Sci Technol 82:450-457

34. Saritha Devi HV, Swapna MS, Sankararaman S (2020) Cost-Effective Green Synthesis of Boron-Rich Carbide Coatings for Infrared Windows and Night-Vision Optics. Phys Status Solidi A 217:1901014

35. Wang S, Li Y, Xing X et al (2018) Low-temperature synthesis of high-purity boron carbide via an aromatic polymer precursor. J Mater Res 33:1659-1670

36. Saritha Devi HV, Swapna MS, Ambadas G et al (2018) Low temperature synthesis of multilayeredhollow microspheres of boron carbide from castor oil for photonic applications. J Appl Phy 124:065303

37. Anselmi-Tamburini U, Munir ZA, Kodera $Y$ et al (2005) Influence of synthesis temperature on the defect structure of boron carbide: experimental and modeling studies. J Am Ceram Soc 88:13821387

38. Fujita T, Guan P, Madhav Reddy K et al (2014) Asymmetric twins in rhombohedral boron carbide. Appl Phys Lett 104:021907

39. Jazirehpour M, Alizadeh A (2009) Synthesis of Boron Carbide Core - Shell Nanorods and a Qualitative Model To Explain Formation of Rough Shell Nanorods. J Phys Chem C 113:1657-1661

40. Guan Z, Gutu T, Yang J et al (2012) Boron carbide nanowires: low temperature synthesis and structural and thermal conductivity characterization. J Mater Chem 22:9853-9860

41. Domnich V, Reynaud S, Haber RA et al (2011) Boron carbide: structure, properties, and stability under stress. J Am Ceram Soc 94:3605-3628

42. Werheit H, Binnenbruck H, Hausen A (1971) Optical Properties of Boron Carbide and Comparison with b-Rhombohedral Boron. Phys Status Solidi B 47:153-158 
43. Bylander DM, Kleinman L, Lee S (1990) Self-consistent calculations of the energy bands and bonding properties of $\mathrm{B}_{12} \mathrm{C}_{3}$. Phy Rev B 42:1394

44. Saritha Devi HV, Swapna MS, Ambadas G et al (2018) Optical Emission Diagnosis of Boron Carbide Synthesized Using Natural Carbon Precursors. Opt Spectrosc 125:928

\section{Figures}

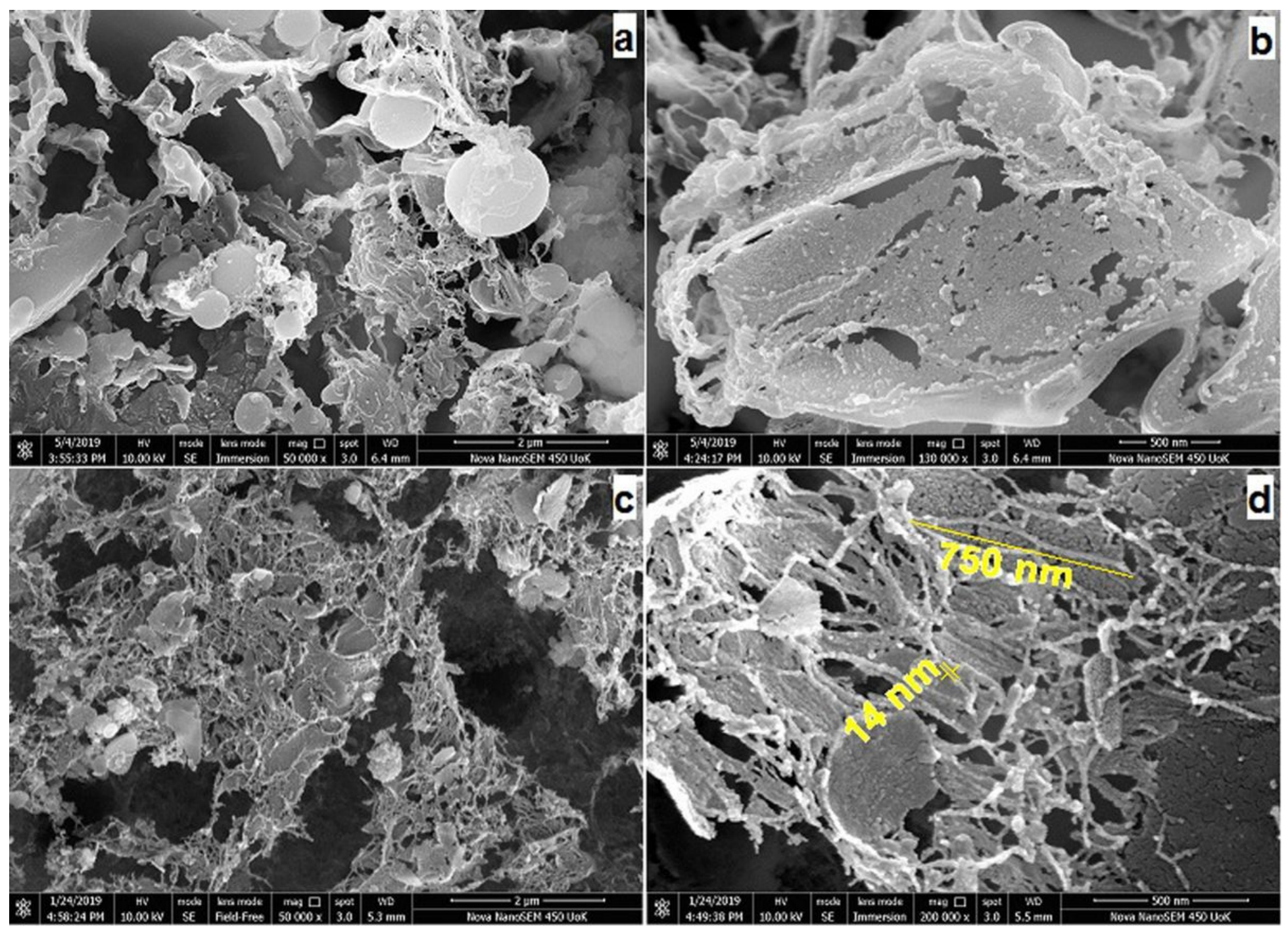

Figure 1

FESEM images of the sample: (a) and (b) annealed at $300^{\circ} \mathrm{C}$; (c) and (d) annealed at $900{ }^{\circ} \mathrm{C}$. 


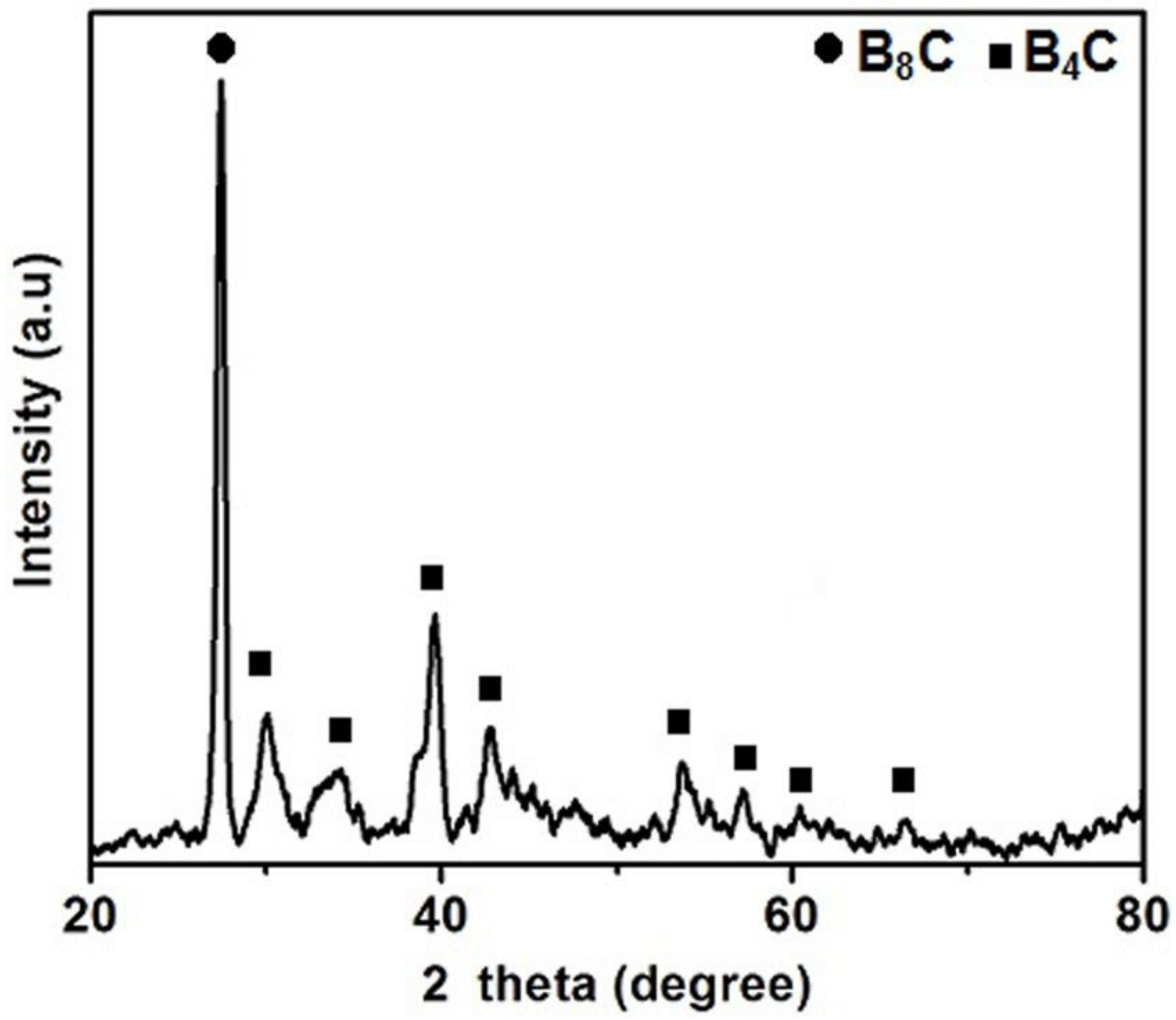

Figure 2

XRD pattern of the $B C$ nanowires synthesized 


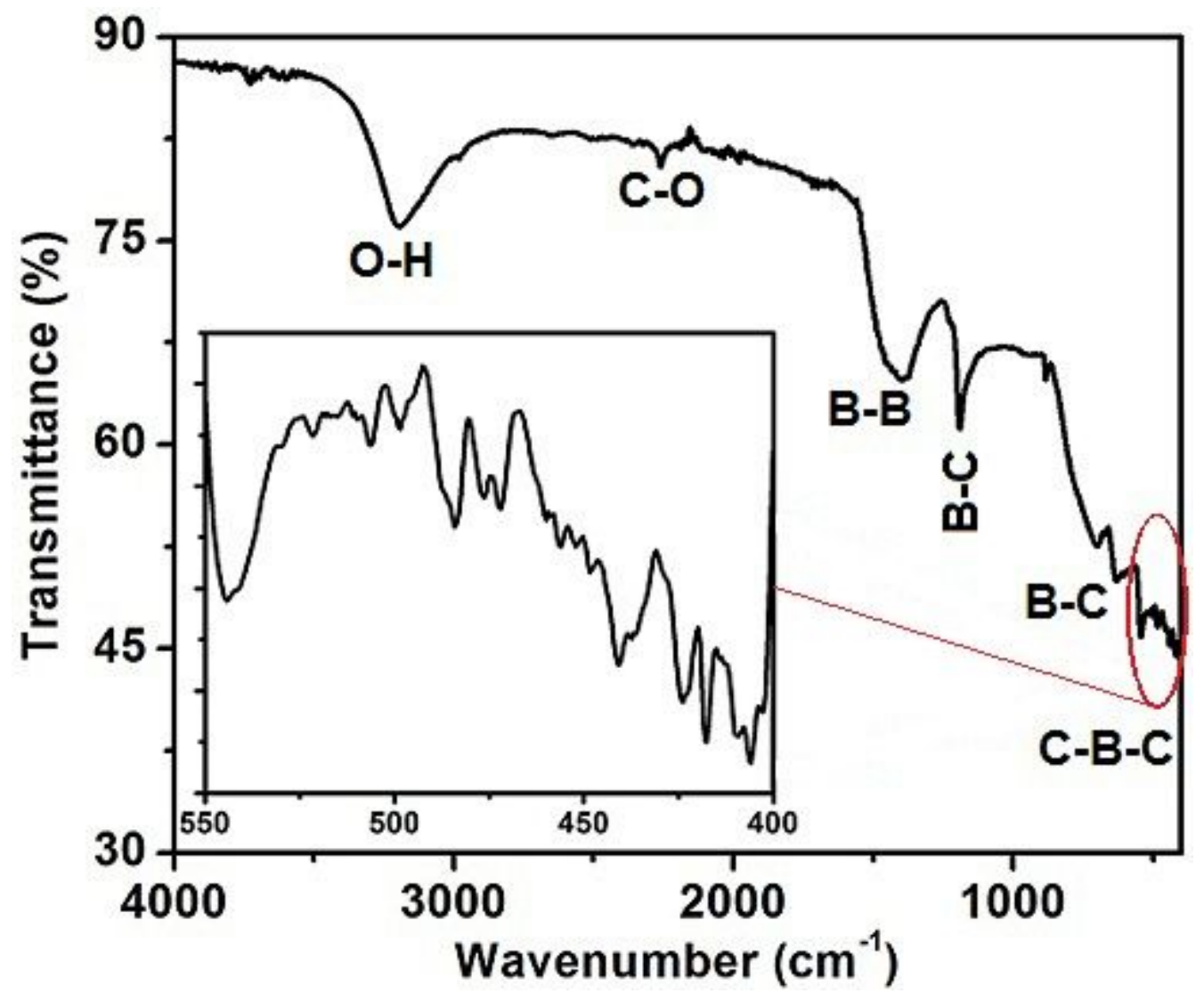

Figure 3

FTIR spectrum of the BC nanowires synthesized.
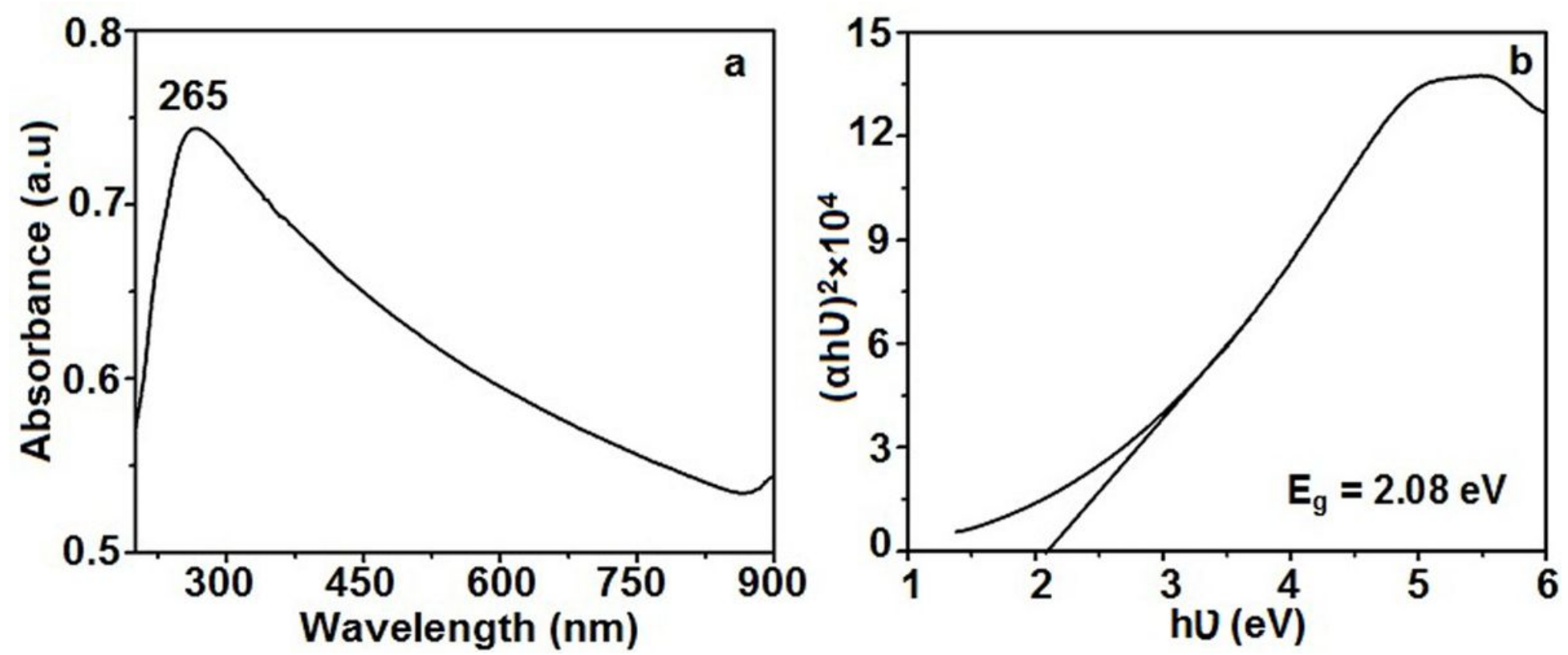

Figure 4

BC NWs - (a) UV-Vis absorption spectrum and (b) Tauc plot. 

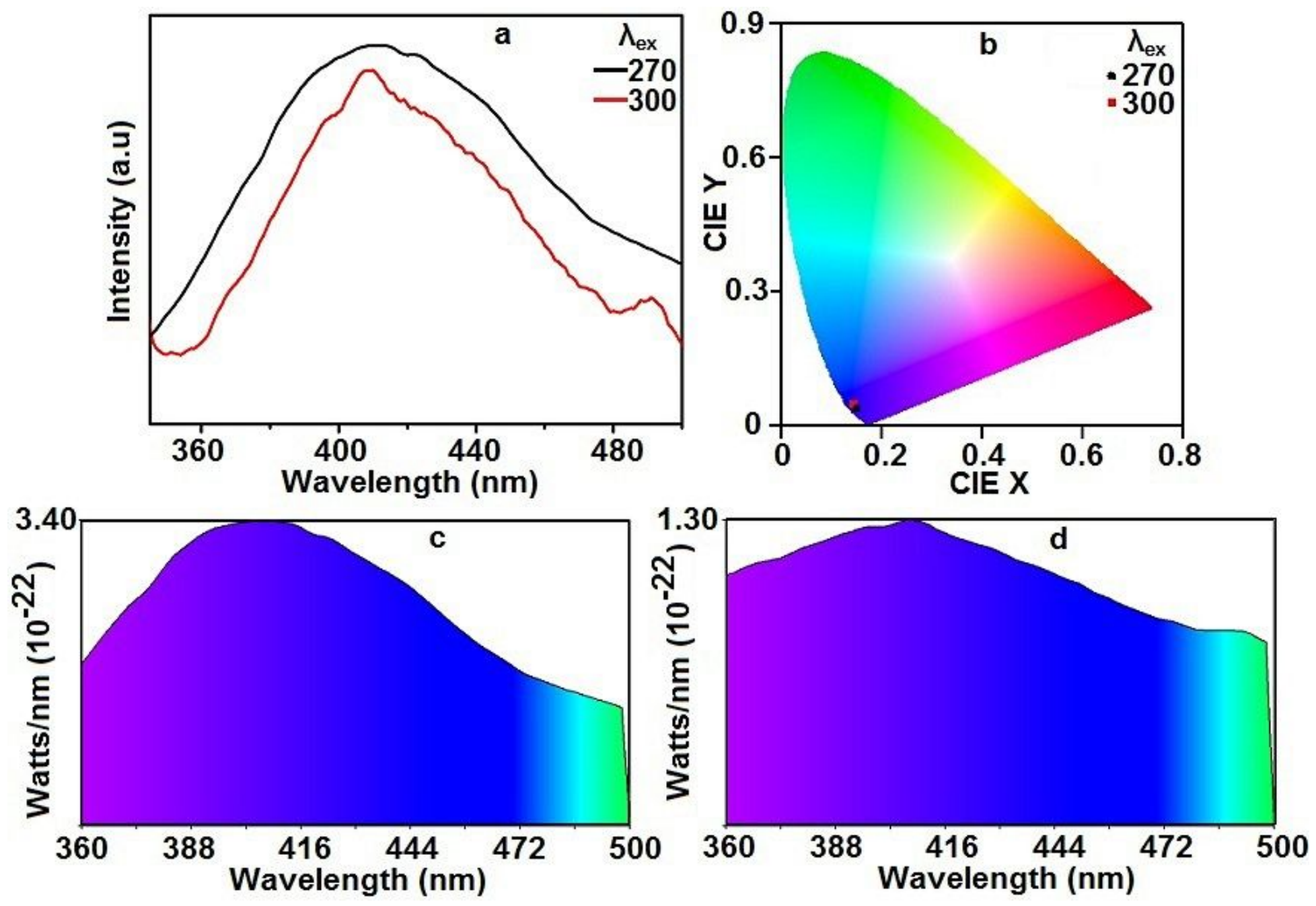

Figure 5

(a) PL spectra of BC NWs for $\lambda$ ex- $270 \mathrm{~nm}$ and $300 \mathrm{~nm}$, (b) CIE plot, (c) the power spectrum for $\lambda$ ex- 270 $\mathrm{nm}$ and (d) power spectrum for $\lambda$ ex- $300 \mathrm{~nm}$. 